Hence it appears that we have here valid evidence that the Gibbsian definition of "displacement" leads in the case of the phenomena of metallic reflection to results more compatible with the experimental facts than does the Maxwellian. This seems to me to justify a comprehensive reconsideration of all of the phenomena of absorbing media in the light of the Gibbsian definition, and suggests that even at this late date we still have something to learn from the paper first presented to this body in 1882 .

\title{
OXIDATIVE·AND PHOSPHORYLATIVE ACTIVITY OF PLANT MITOCHONDRIA*
}

\section{By Adele Millerd,** James Bonner, Bernard Axelrod, $\dagger$ and ROBERT BANDURSKI}

Kgrckhoff Laboratories, California Institute of Technology

Communicated October 1, 1951

The experiments reported in this paper concern the mechanisms involved in plant respiration, particularly those involved in the oxidation of pyruvate. The interest of such a study lies in the fact that although pyruvate is well established as an intermediate in the respiratory oxidation of hexose by plant tissues, ${ }^{1}$ it has not heretofore been possible to bring about the further oxidation of pyruvate in vitro by any enzyme system of plant origin. Studies of the malonate inhibition of plant respiration in vivo have indicated that, in the plant as in animal tissues, pyruvate oxidation is accomplished through the reactions of the Krebs cycle with the participation of a malonate-inhibitable succinoxidase system. ${ }^{2}$ The earlier work of Laties ${ }^{3}$ with cauliflower, of Millerd ${ }^{4}$ with potato and of Bhagvat and $\mathrm{Hill}^{\mathrm{s}}$ with various species has established that the succinoxidase activity of plant tissue is associated with the particulate components of the cytoplasm. It has been found in the present work that a variety of further respiratory enzymes are associated with the same particles. From seedlings of the mung bean, Phaseolus aureus, particles have been isolated which are capable of carrying out all of the reactions of the Krebs cycle including the complete oxidation of pyruvate to $\mathrm{CO}_{2}$ and water.

During the separation of the particulate matter attention must be paid to osmotic concentration, $\mathrm{pH}$ and phosphate concentration of the dispersion medium and the temperature at which the operations are conducted must be kept close to $0^{\circ} \mathrm{C}$. The cytoplasmic particles with which we are concerned are sedimented in 15 minutes by a gravitational field of $10,000 \mathrm{~g}$. after they have been prepared under these conditions. They 
are approximately 0.5 to $2 \mu$ in diameter and thus possess the dimensions characteristic of plant mitochondria. That the active particles are indeed mitochondria is established by the fact that they stain brilliantly with Janus Green B (dye concentration 1:50,000), a property which is unique to intact mitochondria. ${ }^{6}$

Finally, the oxidative metabolism of these plant mitochondria may be coupled to the generation of energy rich phosphate in the form of adenosine triphosphate, ATP, providing a channel through which the energy liberated in respiratory oxidations may be made available to energy consuming reactions of the cell.

Materials and Methods.-Etiolated seedlings of Phaseolus aureus were grown at $26^{\circ} \mathrm{C}$. under a low intensity red light. The seeds were first sterilized by immersion for 10 minutes in $0.5 \% \mathrm{NaOCl}$, soaked in distilled water for 60 minutes, and then planted in vermiculite which had been previously saturated with water. The seedlings were harvested $90 \mathrm{hr}$. later at which stage they were approximately $8 \mathrm{~cm}$. in length.

Thirty gm. of tissue representing the complete aerial portion of the plant were ground for approximately 2 minutes in a mortar with $10 \mathrm{~g}_{\mathbf{A}} \mathrm{n}$. sand and $40 \mathrm{ml}$. of $0.1 \mathrm{M}$ phosphate $\left(\mathrm{KH}_{2} \mathrm{PO}_{4}\right.$ and $\left.\mathrm{Na}_{2} \mathrm{HPO}_{4}\right), \mathrm{pH} 7.1$, containing $0.4 M$ sucrose (solution 1 ). The brei was strained through muslin and clarified by low-speed centrifugation (500 g. for 5 minutes). The residual suspension was then recentrifuged (10,000 g. for 15 minutes) and the supernatant removed by suction. . The residue was resuspended in $20 \mathrm{ml}$. of solution $\mathrm{I}$ and recentrifuged $(10,000 \mathrm{~g}$. for 15 minutes), the supernatant again removed by suction and the residue resuspended in $3.5 \mathrm{ml}$. of solution $\mathrm{I}$. One-half $\mathrm{ml}$. of this preparation, containing from 0.55 to $0.7 \mathrm{mg}$. $\mathrm{N}$, was used as the enzyme in the reaction mixture which in all cases had a total volume of $1.5 \mathrm{ml}$. All steps in the preparation were carried out at $2^{\circ} \mathrm{C}$. or lower while measurements of the metabolic activities of the particles were carried out at $30^{\circ} \mathrm{C}$. Metabolic measurements were continued for a period of one hour unless otherwise stated. The methods used in this preparation are based essentially on the recomimendations of Laties. $^{3}$

Oxidative Ability of Plant Mitochondria.-The oxidations carried out by mitochondrial preparations result in the consumption of oxygen and may be followed manometrically. The data of table 1 show that principal acids of the Krebs cycle are oxidized by the system. In this experiment the rates of oxidation of the various substrates, determined under conditions appropriate for maximal rate of pyruvate oxidation, may be compared. It is evident however that citrate, $\alpha$-ketoglutarate, succinate and pyruvate are oxidized more rapidly than are malate and fumarate.

For the oxidation of pyruvate, the simultaneous oxidation of a small amount of one of the acids of the Krebs cycle, as for example malate, is 
essential as is shown in table 2. The respiratory quotient for the oxidation of pyruvate under these circumstances is 1.3 , corresponding to the expected value for the complete oxidation to $\mathrm{CO}_{2}$ and water.

Other acids of the Krebs cycle may be substituted for malate in its role of promoting the oxidation of pyruvate. The data of table 3 show that these acids are approximately equally effective in this function.

TABLE 1

Oxidation of Acids of the Kregs Cycle by Cytoplasmic Particles of Mung Bean

Enzyme
Enzyction MIXTURE
Enzyme + citrate
Enzyme $+\alpha$-keto-glutarate
Enzyme + succinate
Enzyme + fumarate
Enzyme +1 -malate
Enzyme +1 -malate
Enzyme +1 -malate ${ }^{b}+$ pyruvate

SUBSTRATE CONCENTRATION

$\mathrm{O}_{2}$ CONSUMPTION CU. MM./HR./MG. $\mathbf{N}$

${ }^{a}$ Also contains sucrose $0.3 \mathrm{M}$, phosphate buffer $0.05 \mathrm{M}$, ATP $5 \times 10^{-4} \mathrm{M}$ and $\mathrm{MgSO}_{4}$ $10^{-3} M$.

${ }^{b}$ Malate concentration, $1.7 \times 10^{-3} \mathrm{M}$.

\section{TABLE 2}

Catalytic Effect of Malate on Pyruvate Oxidation

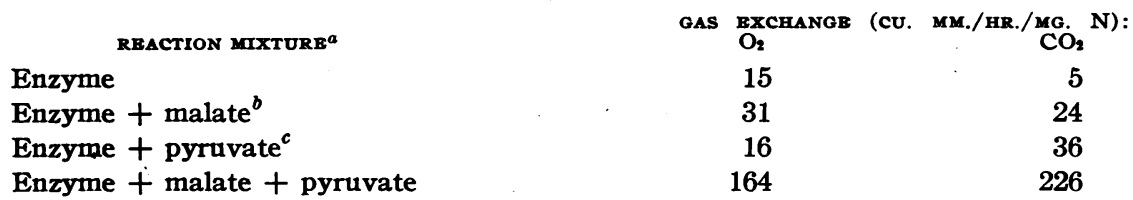

R. Q. for pyruvate oxidation $=1.3$.

${ }^{a}$ Also contains sucrose $0.3 \mathrm{M}$, phosphate buffer $0.05 \mathrm{M}$, ATP $5 \times 10^{-4} \mathrm{M}$ and $\mathrm{MgSO}_{4}$ $10^{-3} M$.

${ }^{b}$ 1-Malate $1.7 \times 10^{-3} M$ throughout.

${ }^{c}$ Pyruvate $2 \times 10^{-2} M$ throughout.

Cofactor Requirements of Plant Mitochondria.-The cytoplasmic particles of mung bean, when appropriately prepared, are-strikingly independent and require no additions of coenzymes or other cofactors other than catalytic amounts of a Krebs cycle acid in order to oxidize pyruvate. Thus the particles exhibit no requirement of or response to added cytochrome c; a property in which they differ strikingly from particulate 
preparations of plant succinoxidase such as have been recently described. ${ }^{5,} 7$ This lack of requirement for exogeneous cytochrome $c$ appears to be associated with the integrity of the present material and is apparently related to the method of preparation since by a slight variation in the method, namely by omitting or lowering the concentration of phosphate in the grinding medium, it is possible to obtain particles which do respond

TABLE 3

\section{Catalytic Effect of Krebs Cycle Acins on Pyruvate Oxidation ${ }^{a}$}

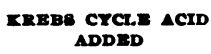

None

Fumarate

Malate

Succinate

$\alpha$-Ketoglutarate

Citrate

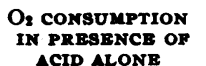
CU. MM./HR./MO. N IN
PRESENCE OF $2 \times 10^{-2}$ $\triangle C I D \triangle L O N R$

CONCENTRATION, M

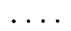

$1.7 \times 10^{-3}$

$1.7 \times 10^{-3}$

$1.7 \times 10^{-3}$

$1.7 \times 10^{-3}$

$1.3 \times 10^{-2}$
0

3

18

18

20

21 M PYRUVATE

a Reaction mixture contains enzyme, sucrose $0.3 \mathrm{M}$, phosphate buffer $0.05 \mathrm{M}, \mathrm{ATP}$ $5 \times 10^{-4} M$ and $\mathrm{MgSO}, 10^{-2} M$.

TABLE 4

Relation of Method of Preparation to Cytochrome C Regutrement of Cytoplasmic Particles

Standard Method

REACTION MXTURE ${ }^{a}$

Enzyme

Enzyme + succinate $\left(2 \times 10^{-2} M\right)$

Enzyme + succinate $\left(2 \times 10^{-2} M\right)+$ cytochrome c $\left(10^{-6} M\right)$

Modified Method ${ }^{b}$

REACTION MIXTURE *

Enzyme

Enzyme + succinate $\left(2 \times 10^{-2} M\right)$

Enzyme + succinate $\left(2 \times 10^{-2} M\right)+$ cytochrome c $\left(10^{-5} M\right)$

a Also contains sucrose $0.3 \mathrm{M}$, and phosphate bufer $0.05 \mathrm{M}$.

b Phosphate omitted from initial grinding mixture.

${ }^{c}$ Also contains sucrose $0.2 \mathrm{M}$, and phosphate buffer $0.05 \mathrm{M}$. O. CONSUMTrION,
co. Mm./HR./Me. $\mathrm{N}$ 202 204 Co. 0 7 45

to added cytochrome $\mathrm{c}$ as is shown in table 4. The oxidations carried out by the system are therefore apparently mediated by the cytochrome system.

Although the only. supplement to the reaction mixture required for the oxidation of pyruvate by mung bean particles is a catalytic amount of one of the acids of the Krebs cycle, still the rate of oxidation is increased 
by the addition of further substances to the reaction mixture. The materials which exhibit such a quantitative influence on rate of substrate oxidation are ATP and $\mathrm{Mg}$ ions. The data of table 5 show that these two materials are effective individually but that together they may increase rate of pyruvate oxidation threefold or more. This effect is not unique to ATP but is shared equally by ADP, adenosinediphosphate, and AMP, adenosine-5-phosphate. Adenosine-3-phosphate, yeast adenylic acid, is totally ineffective. These relations are summarized in table 6 .

TABLE 5

Effect of Catalytic Amounts of ATP and of Mg Jons on the Rate of Pyruvate Oxidation by Cytoplasme Particles

\begin{tabular}{|c|c|}
\hline REACTION MTXTURE ${ }^{a}$ & 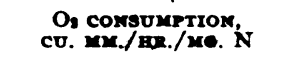 \\
\hline Enzyme + pyruvate + malate & 60 \\
\hline Enzyme + pyruvate + malate + ATP & 97 \\
\hline Enzyme + pyruvate + malate $+\mathrm{Mg}$ ions & 135 \\
\hline Enzyme + pyruvate + malate $+\mathbf{A T P}+\mathbf{M g}$ ions & 189 \\
\hline
\end{tabular}

TABLE 6

Equivalence of ATP, ADP and AMP in Increasing the Rate of Pyruvate Oxidation by Cytoplasmic Particles

Enzyme

SUPPLEMENT TO REACTION MXXURE"a

Os consumption

Enzyme + ATP $\left(10^{-3} M\right)$ co. MM./HR./Mo. N

Enzyme + ADP $\left(10^{-3} M\right)$ 58

111

107

Enzyme + AMP $\left(10^{-3} M\right)$

102

Enzyme + adenosine-3-phosphoric acid $\left(10^{-3} M\right)$

58

a Contains pyruvate $2 \times 10^{-2} M$ as the substrate. Also contains 1 -malate $1.7 \times$ $10^{-3} \mathrm{M}$, sucrose $0.3 \mathrm{M}$, phosphate buffer $0.05 \mathrm{M}$ and $\mathrm{MgSO}_{4} 10^{-3} \mathrm{M}$.

The standard method for the preparation of cytoplasmic particles active in the oxidation of the Krebs cycle acids includes the use of phosphate in the medium in which the initial grinding is carried out. The presence of phosphate in the grinding medium appears to be essential if active particles are to be obtained from mung bean. In addition, however, the presence of phosphate in the reaction mixture is essential to maximum oxidative activity as is shown in figure 1 . In this experiment, the particles were prepared in phosphate medium according to the standard procedure, washed free of phosphate by centrifugation in a solution of sucrose and $\mathrm{KCl}$, and the rate of oxidation of $\alpha$-ketoglutarate determined as a function of phosphate concentration in the reaction 
mixture. This and other data show a well-marked optimum phosphate concentration in the neighborhood of $0.01 M$. None of the preparations obtained were entirely free of inorganic phosphate and therefore an absolute requirement of this system for phosphate has not been established.

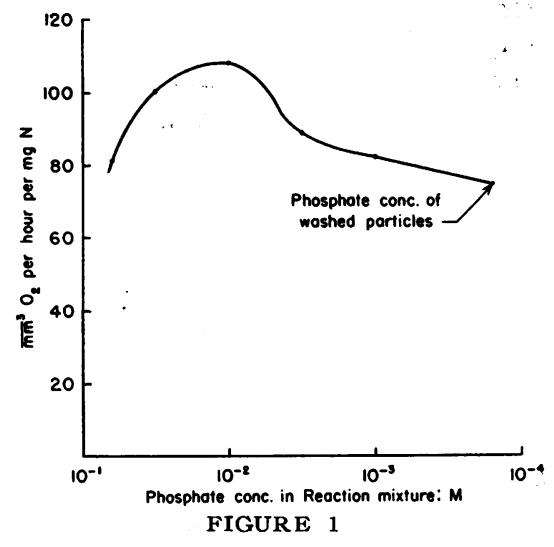

Rate of oxidation of $\alpha$-ketoglutarate by mung bean particles as a function of phosphate concentration in the reaction mixture. Reaction mixture also contains sucrose $0.3 M, \mathrm{KCl} 0.05 M, \mathrm{MgSO}_{4} 10^{-3} M$, AMP $10^{-3} M$. and $\alpha$-ketoglutarate $2 \times$ $10^{-2} M$.

has now been possible to show unequivocally that substrate oxidation results in the incorporation of inorganic $P$ into ATP. For this experiment plant mitochondria were allowed to oxidize $\alpha$-ketoglutarate in the presence of ATP and $\mathrm{P}^{32}$ labeled inorganic phosphate. A portion of the ATP added was degraded to ADP by a mechanism to be discussed below making possible the resynthesis of ATP at the expense of inorganic phosphate of the reaction mixture. After a period of reaction, the ATP was reisolated by two dimensional paper chromatography. ${ }^{8}$ The ATP now contained $\mathrm{P}^{32}$ as is shown in table 7. Appearance of inorganic phosphate in energy-rich form was almost wholly dependent on the simultaneous oxidation of substrate as is shown in table 7 . The production of energy-rich phosphate bonds as a result of oxidations of the Krebs cycle not only occurs in the higher plant but also follows the general pattern already elucidated for animal tissues.

Plant mitochondria not only possess the ability to generate ATP at the expense of energy derived from substrate oxidation but they also appear capable of utilizing ATP for at least one synthetic reaction. The enzyme, hexokinase, which catalyzes the reaction between ATP and hexose to form hexose-6-phosphate is associated with the cytoplasmic particles 
of mung bean, as prepared by the present technique. Thus in the experiment, table $7, \mathrm{P}^{32}$ labeled hexose phosphate as well as ATP appeared in the reaction mixture during the course of substrate oxidation. Hexose, derived from the sucrose of the suspending medium by the action of particlebound invertase, served as the substrate for mitochondrial hexokinase. The participation of phosphorylase in this reaction is excluded since labeled hexose phosphate appeared only as a result of substrate oxidation.

Discussion and Summary.-The respiratory oxidation of pyruvate to $\mathrm{CO}_{2}$ and water has been achieved with an enzyme system prepared from a higher plant, the mung bean. The enzymes involved are all associated with cytoplasmic particles which appear to be identical with mitochondria. It is of special interest in this connection that the oxidase system associated with these particles and hence responsible for the respiratory oxidation of pyruvate in this plant preparation is apparently the cytochrome system. The presence of the cytochrome system in plants is well known although it is equally true that other oxidase systems are present in many plant tis-

TABI,E 7

Incorporation of Inorganic $P^{32}$ into ATP and Hexose Phosphate during MITOCHONDRIAL OXIDATION ${ }^{a}$

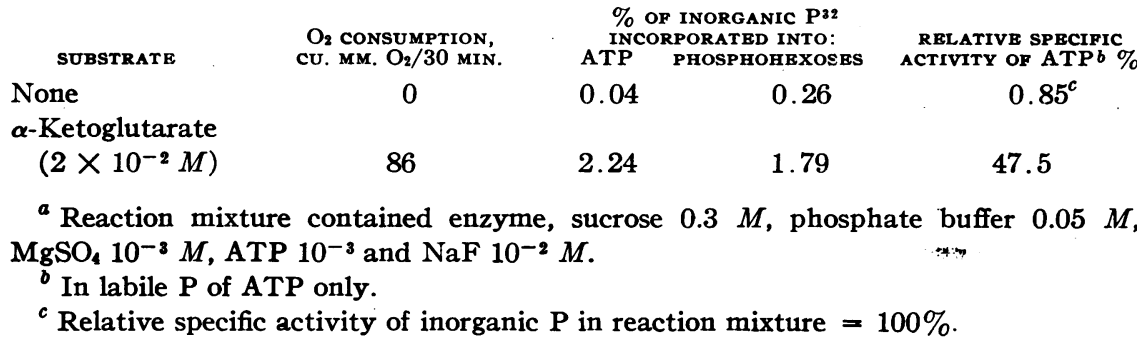

sues. It has been inferred from inhibition experiments in vivo that the cytochrome system mediates a portion or all of the respiration of certain plant tissues. The findings presented above however now directly implicate the cytochrome system in one of the major respiratory processes, the complete oxidation of pyruvate. The fact that mitochondrial oxidation of pyruvate requires the simultaneous oxidation of an acid of the Krebs cycle, as well as the ability of the particles to oxidize these materials, provides further support for the view, based on in vivo experiments that respiratory oxidation of pyruvate in the plant as in the animal may proceed by the successive steps of the Krebs' cycle. ${ }^{2}$

Mitochondrial oxidation by the mung bean preparation has been linked to the formation of energy-rich phosphate bonds in the form of ATP. This fact, together with the close similarity or identity of higher plant ATP to that of animals and microorganisms, ${ }^{9}$ indicates that the mechanics 
of energetic coupling in the higher plant are not dissimilar from those of animal tissues.

* Report of work supported in part by the Herman Frasch Foundation for Agricultural Chemistry.

** Predoctoral Fellow, French Foundation. Recipient of Fulbright travel grant, administered by the Institute of International Education.

† Enzyme Research Division, Bureau of Agriculture and Industrial Chemistry, U. S. Department of Agriculture, Albany, Calif.

1 James, G. M., and James, W. O., Nerw Phytol., 39, 266-270 (1940); Bonner, J., and Wildman, S., Arch. Biochem., 10, 497-518 (1946).

2 Bonner, J., Arch. Biochem., 17, 311-326 (1948); Laties, G., Ibid., 22, 8-15 (1040).

2 Laties, G., Abstracts of Am. Soc. Plant Physiol., June, 1951, p. 2.

- Millerd, A., Proc. Linnean Soc., New South Wales, 74, xxvi (1949); Ibid., 76 123132 (1951); also summarized in Idem, 75, iii (1950).

- Bhagvat, K., and Hill, R., New Phytol., 50, 112-120 (1951).

- See, for example, Ludford, R. J., Biol. Rev., 8, 357-369 (1933).

' Stafford, H., Abstracts of Am. Soc. of Plant Physiol., September, 1951, p. 13.

s Bandurski, R., and Axelrod, B., J. Biol. Chem. 193, 405-410 (1951).

- Albaum, H., Ogur, M., and Hirshfeld, A., Fed. Proc., 8, 179 (1949); Axelrod, B., and Bandurski, R., Abstracts of Am. Soc. Plant Physiol., September, 1951, p. 28.

HYBRIDIZATION AND EMBRYONIC TEMPERATURE ADAPTATION STUDIESOF RANA TEMPORARIA AND RANA SYLVATICA

\author{
By JOHN A. MOORE
}

\title{
Departments of Zoology, Barnard College and Columgin Untveratet
}

Communicated by Franz Schrader, November 2, 1951

Rana temporaria and similar medium-sized, black-masked frogs are found throughout nearly the entire Holarctic region. In Europe and Asia the common species are Rana temporaria, Rana arvalis, Rana agilis, Rana japonica and Rana choachiooensis. In North America the representatives are Rana sylvatica and perhaps several western species.

The close resemblance of Rana sylvatica and Rana temporaria has been noted by many authors. This resemblance could be an indication of genetic similarity or an independent development of like color patterns.

In an effort to differentiate between these alternative hypotheses, comparison of the two species on the basis of characters other than pigmentation is desirable. Previous work has shown that embryonic temperature tolerance and rate of development are highly species specific in the amphibia. Consequently it is of some interest to compare the embryonic temperature tolerance and rate of development of Rana temporaria with that of Rana sylvatica. 